\title{
Novel venom-based peptides (P13 and its derivative-M6) to maintain self-renewal of human embryonic stem cells by activating FGF and TGF $\beta$ signaling pathways
}

Rui Ma ${ }^{1,2+}$, Zhili Ren ${ }^{1,3+}$, Bin Li ${ }^{1,2}$, Shirley W. I. Siu ${ }^{4}$, Guokai Chen ${ }^{1,3}$ and Hang Fai Kwok ${ }^{1,2^{*}}$ (D)

\begin{abstract}
Background: In our previous study, a venom-based peptide named Gonearrestide (also named P13) was identified and demonstrated with an effective inhibition in the proliferation of colon cancer cells. In this study, we explored if P13 and its potent mutant M6 could promote the proliferation of human embryonic stem cells and even maintain their self-renewal.

Methods: The structure-function relationship analysis on P13 and its potent mutant M6 were explored from the molecular mechanism of corresponding receptor activation by a series of inhibitor assay plus molecular and dynamics simulation studies.
\end{abstract}

Results: An interesting phenomenon is that P13 (and its potent mutant M6), an 18AA short peptide, can activate both FGF and TGF $\beta$ signaling pathways. We demonstrated that the underlying molecular mechanisms of P13 and M6 could cooperate with proteoglycans to complete the "dimerization" of FGFR and TGF $\beta$ receptors.

Conclusions: Taken together, this study is the first research finding on a venom-based peptide that works on the FGF and TGF- $\beta$ signaling pathways to maintain the self-renewal of hESCs.

Keywords: Venom peptide, Self-renewal, Embryonic stem cell, Peptide modification, Pluripotency

\section{Introduction}

The advantages of venom-based peptides from animals such as scorpions, spiders, and snakes are their stable structures and high specificities for target molecules due to a hundred million years of adaptive evolution $[1,2]$. Recently, our research group developed a high-throughput screening platform and identified a venom peptide named Gonearrestide (18AA, MW2194, also called P13) from an

\footnotetext{
*Correspondence: hfkwok@um.edu.mo

${ }^{\dagger}$ Rui Ma and Zhili Ren contributed equally to this work.

'Institute of Translational Medicine, Faculty of Health Sciences, University of Macau, Avenida de Universidade, Taipa, Macau SAR

${ }^{2}$ Cancer Centre, Faculty of Health Sciences, University of Macau, Avenida de Universidade, Taipa, Macau SAR

Full list of author information is available at the end of the article
}

in-house scorpion venom library [3]. In our previous study, we demonstrated that P13 could effectively inhibit the proliferation of colon cancer cells via triggering the cell cycle arrest in the G1 phase. It is well known that the relationship between the structure and function of ion channels, such as Voltage-sensitive $\mathrm{Na}^{+}$channels and $\mathrm{K}^{+}$ channels, can be studied by using venom-based peptides [4-6]. However, the relationship between venom-based peptides and receptors involved in stem cell self-renewal or differentiation has rarely been reported.

Human embryonic stem cell (hESC) therapy has been proposed for regenerative medicine and tissue replacement after injuries or diseases such as Parkinson's disease, spinal cord injury, and diabetes [7-9]. Although 
stem cells have extensive self-renewal potential, they require high regenerative conditions to maintain pluripotency in vitro [10]. The $\mathrm{mTeSR}^{\mathrm{Tm}} 1$ and Essential $8^{\mathrm{mm}}$ (E8) media are the main products on the market for the growth and expansion of human pluripotent stem cells (hPSCs), ES cells, and induced pluripotent stem cells (iPS cells) [11, 12]. Chen et al. developed the E8 medium that has few components and easy quality control as compared to $\mathrm{mTeSR}^{\mathrm{min}} 1$ (19 components) $[12,13]$. The E8 medium is Xeno- and feeder-free and has eight components: DMEM/F12, FGF2, TGF $\beta 1$, insulin, L-ascorbic acid, selenium, $\mathrm{NaHCO} 3$, and transferrin. The Essential $6^{\text {Th }}$ Medium (E6) is a medium based on the E8 medium but without two components, FGF2 and TGF $\beta 1$, which supports the reprogramming of somatic cells and the differentiation of hPSCs.

Interestingly, when P13 was added to the E8 medium to culture human ES cells, P13 did not inhibit the growth of human ES cells. Instead, it promoted their massive expansion. The FGF and TGF $\beta$ signaling pathways have been reported to promote the self-renewal mechanism of hESCs (Supplementary Fig. S1) [14-16]. The TGF $\beta$ signal-activated SMADs directly bind with the NANOG proximal promoter and upregulate the expression of NANOG [14]. Pluripotency-associated key genes such as NANOG, OCT4, and SOX2 maintain the long-term self-renewal ability of the hESCs [17]. Through this study, we revealed that P13 upregulated the protein expression of $\mathrm{p}$-Erk1/2 and p-Smad2 and activated the expression of OCT4, SOX2, and NANOG, the important factors for maintaining the self-renewal ability of the hESCs.

However, maintaining the self-renewal mechanism of the hESCs requires a relatively higher concentration of $\mathrm{P} 13$, which is not ideal for the hESC culture application. To find a potent isoform of P13, the P13 "binding domain" was modified, and the in-depth study of the relationship between structure and function was performed from starting at the molecular mechanism of corresponding receptor activation. One of the P13 mutants, M6, showed a much higher proliferative activity. Furthermore, two FGFR inhibitors and three TGF- $\beta$ receptor inhibitors were used to confirm the signaling pathway mechanism involved in P13 and its mutant M6 (Supplementary Fig. S1). In addition, molecular modeling and simulations were used to predict the binding modes of P13 and M6 to FGFR and provide insights on the molecular mechanism to FGFR activation induced by the peptides in the hESCs. After a series of inhibitor assay and molecular dynamics simulation studies, we found that underlying molecular mechanisms of P13 and its potent mutant M6 can cooperate with proteoglycans to complete the "dimerization" of FGFR and TGF $\beta$ receptors. As a result, we found that P13 is the first venom-based peptide that acts on both the TGF- $\beta$ and FGF signaling pathways to promote the self-renewal of the hESCs.

\section{Materials and methods \\ Human ES cell culture}

The human ES cells (hESCs, H1 from WiCell Research Institute, Inc., Madison, WI, http://www.wicell.org) were maintained in an E8 medium using matrigel-coated tissue culture plates [12]. The E8 medium had eight components: DMEM/F12, L-ascorbic acid-2-phosphate magnesium (64 $\mathrm{mg} / \mathrm{l})$, sodium selenium $(14 \mu \mathrm{g} / \mathrm{l})$, insulin $(19.4 \mathrm{mg} / \mathrm{l})$, NaHCO3 $(543 \mathrm{mg} / \mathrm{l})$, transferrin $(10.7 \mathrm{mg} / \mathrm{l})$, and the FGF2 $(100 \mu \mathrm{g} / \mathrm{l})$ and TGF $\beta 1(2 \mu \mathrm{g} / \mathrm{l})$ growth factors. The cells were passaged every 3-4 days once the cells reached 80 $85 \%$ confluency by using the EDTA method in the presence of Y-27632 as previously described [18]. The E8 medium had to be changed every day. The hESCs with normal karyotypes were used in less than the passage of P50.

\section{Survival assay}

The human ES cells were dissociated with TrypLE (Gibco) for 5-8 $\mathrm{min}$ at room temperature and neutralized with the medium containing $0.5 \%$ BSA. The cell counts were determined using a BD Accuri C6 flow cytometer and normalized to the original cell number that was plated.

\section{The modification of P13}

As per the Cardin-Weintraub model [-X-B-B-X-B-X-], in which $B$ is a basic residue and $X$ is a hydropathic residue [19], P13 was mutated to synthesize its derivate P13-M5 (Supplementary Table S1). The heparin-binding affinity of the observed basic amino acid arginine was 2.5 times more than lysine [20-22]. So, the two lysines of P13-M5 were mutated into two arginines to get the mutant P13-M6. To investigate the function of the Nterminal P13 key amino acids, two other mutants, P13M10 and P13-M11, were synthesized based on P13-M6 (Supplementary Table S1).

\section{The immunostaining of human ES cells treated with fluorescently labeled P13/M6}

The human ES cells were cultured on sterilized coverslips, and a 12-well plate was coated with matrix gel at a concentration of $1 \mathrm{mg} / \mathrm{ml}$ for $1-2 \mathrm{~h}$. The cells were washed with the DMEM-F12 medium after $24 \mathrm{~h}$, and the E8 medium was changed and treated with fluorescently labeled peptide for $24 \mathrm{~h}$. Then, the cell membrane was stained using the CellMask ${ }^{\mathrm{m}}$ Deep Red plasma membrane (Thermo Fisher) and incubated at $37^{\circ} \mathrm{C}$ for 10 min. The staining solution was removed, and $200 \mu \mathrm{l}$ $4.0 \%$ formaldehyde was added to the medium and incubated at $37{ }^{\circ} \mathrm{C}$ for $10 \mathrm{~min}$. The medium was then 
removed, and the cells were washed with $1 \mathrm{X}$ PBS three times. The cells were incubated with $10 \mu \mathrm{l}$ DAPI (DNA stain) and the mounting medium for $1 \mathrm{~min}$, and the cover glass was mounted. The coverslip was sealed with nail polish to prevent drying. The samples were imaged using a Carl Zeiss Confocal LSM710 microscope.

\section{The expression of $p$-Erk1/2 and p-Smad2 in the human ES} cells treated with P13, M6, and small molecular inhibitors The human ES cells (H1) were seeded into the 12-well plate with an E8 medium. The medium was changed to E6 after $24 \mathrm{~h}$. The human ES cells were incubated at 5\% $\mathrm{CO} 2$ and $37^{\circ} \mathrm{C}$ for $20-24 \mathrm{~h}$, the P13 and M6 peptides were added, and the cells were harvested using RIPA buffer after $1 \mathrm{~h}$.

The human ES cells (H1) were seeded into the 12-well plate with an E8 medium. The medium was changed to E6 after $24 \mathrm{~h}$. The human ES cells were incubated at 5\% $\mathrm{CO} 2$ and $37^{\circ} \mathrm{C}$ for $20-24 \mathrm{~h}$, and certain concentrations of FGFR inhibitors-AZD4547 [23], PD173074 [24], and TGF $\beta$ receptor inhibitors LDN193189 [25], SB431542 [26], and A8301 [27, 28] —were added according to the layout (Under the conditions of TGF $\beta$ receptor inhibitors, three 12-well plates were arranged in the experiment (a total of 22 conditions in Fig. 5b). The three 12well plates were LDN193189, SB431542, and A8301 inhibitor, respectively. Each plate also had E6 without inhibitor as a blank control; under the conditions of FGFR inhibitors, the experiment arranged two 12-well plates (a total of 14 conditions in Fig. 5c). One plate was AZD4547 inhibitor and the other was PD173074, and each plate had E6 without inhibitor as a blank control; under the conditions of AZD4547 and A8301 double inhibitors, a 12-well plate was arranged in the experiment (a total of 12 conditions in Fig. 5d). A 12-well plate was arranged for the verification experiments of single inhibitor AZD4547 and A8301 and validation of simultaneous addition of dual inhibitors AZD4547/A8301, and E6 without inhibitor as a blank control.) and incubated for $3 \mathrm{~h}$; then certain concentrations of P13 and M6 peptide were added, and the cells were collected using RIPA buffer after $1 \mathrm{~h}$.

\section{Western blotting}

For the western blotting of soluble proteins, the human ES cells were harvested using RIPA buffer with benzonase, protease inhibitors, and phosphatase inhibitors. The protein concentration was measured using the Pierce $^{\mathrm{Tm}}$ BCA Protein Assay Kit (Thermo Fisher). Twelve percent SDS-PAGE gel was used, and the proteins in the gel were transferred onto a nitrocellulose membrane. The membrane was blocked using 5\% defatted milk in a $1 \mathrm{xPBST}$ buffer for an hour at room temperature with shaking, incubated with the primary antibody at $4{ }^{\circ} \mathrm{C}$ overnight, and then with the secondary antibody-HRP for $1 \mathrm{~h}$. The PVDF membrane was washed three times with $1 \mathrm{xPBST}$ for $10 \mathrm{~min}$ at the end of each incubated antibody step. The Pierce ${ }^{\mathrm{Tm}}$ ECL Western Blotting Substrate was used to detect chemiluminescence (Thermo Fisher) on the ChemiDoc Imaging System (Bio-Rad).

\section{Total RNA extraction and qPCR to check self-renewal markers}

The hESCs' RNA was extracted using the RNeasy Mini Kit (QIAGEN). One thousand nanograms per tube of isolated RNA was reverse transcribed into cDNA using the High-Capacity cDNA Reverse Transcription Kit (Thermo Fisher). The qPCR was performed on the BioRad CFX96 Touch Real-Time PCR using the PowerUp SYBR Green Master Mix (Thermo Fisher). The observed primer sequences are listed in Supplementary Table S2. All the experiments were performed in triplicates, and the relative gene expression was normalized with GAPDH.

\section{CDOCKER of A8301 inhibitor to TGF $\beta$ receptor}

CDOCKER is a CHARMM-based molecular dynamics (MD) scheme to dock ligands into a receptor binding site by adopting high-temperature kinetics to search for flexible conformational spaces of ligand molecules and simulating the annealing to map each conformation at the active receptor site. The TGF-beta receptor type-1 (PDB ID: 3TZM) was selected as the acceptor, the small molecule inhibitors contained in the crystal structure were deleted, and the site sphere was selected from the PDB site records. Then, A8301 was chosen as the ligand. The parameters set were as follows: 1000 random conformation dynamics steps, $1000 \mathrm{k}$ dynamics target temperature; 2000 simulated annealing heating steps, $700 \mathrm{k}$ heating target temperature, 5000 cooling steps, and $300 \mathrm{k}$ cooling target temperature; forcefield: CHARMM [29]. The Discovery Studio v17.2.0 commercial software was used.

\section{Molecular dynamics (MD) simulations}

Molecular dynamics (MD) simulations were used to investigate the effects of the two venom-based peptides on the structure and dynamics of the FGFR dimer. We used the PDB entry 1FQ9 ( $3 \AA$ resolution) [30] as starting structures for the receptor, its ligand, and the co-factor. This PDB contains two FGFs, two FGFRs, and two heparan sulfate (HS) molecules bound in a stable ternary complex. On the other hand, the initial coordinates of P13 and M6 peptides were obtained by prediction using the PEP-FOLD3 server [31]. The C-termini of both peptides were amidated in accordance with the experimental forms. The simulation systems with four different setups were constructed: the crystal 2:2:2 FGF:FGFR:HS complex, the apo 2:2 FGFR:HS complex, and the 2:2 FGFR: 
HS complex bound with chains of P13 or M6. We believe that multiple peptides were required to exert effects on the biological function of the protein, so we performed preliminary studies for systems with 10, 20, and 30 chains of P13 and M6 with short MD simulations. These peptides were randomly placed in the solvent phase of the system and allowed to equilibrate around the protein complex. Initially, position-restraints were applied on all heavy atoms of the protein complex to prevent the change in the receptor conformation. As the number of peptides contacted with the complex was converged after $200 \mathrm{~ns}$, the position restraints were removed and the systems were simulated for another 200 ns. Based on the observed better stability of the protein receptor (Supplementary Fig. S2), we focused our study on the 20-chain peptide systems and extended these simulations until $500 \mathrm{~ns}$.

Topology files for the simulation systems were generated using the CHARMM-GUI web interface [32] with the following options: (1) fix the missing inner residues in the FGFR chain B (residue 293 to 307); (2) model four suggested disulfide bonds (178 and 230, 277 and 341 of the FGFR chain A and B); (3) glycosylation of both heparin molecules; (4) add counter ions to neutralize the system; and (5) solvate the entire complex with water molecules in a rectangular box. The prepared systems contain approximately 200,000 atoms in a box of $13.0 \times$ $13.0 \times 13.0 \mathrm{~nm}^{3}$ (Supplementary Table S3). All simulations were performed under periodic boundary conditions using GROMACS version 5.0.7 [33]. The proteins, peptides, and heparins were modeled by the CHARMM $36 \mathrm{~m}$ force field [34] and the water molecules by TIP3P [35]. Short-range interactions were cutoff at $1.2 \mathrm{~nm}$ with the use of the switching potential for van der Waals interactions starting at $1.0 \mathrm{~nm}$. Long-range interactions were treated by particle mesh Ewald [36] with a Fourier spacing of $0.12 \mathrm{~nm}$. Bonds with a hydrogen atom were constrained using the LINCS [37] and SETTLE [38] algorithms, so a time step of $2 \mathrm{fs}$ could be used. Production simulations were performed in the isothermal-isobaric (NPT) ensemble. The Nosé-Hoover thermostat [39] was used at $300 \mathrm{~K}$ with a coupling constant of $1.0 \mathrm{ps}$. The pressure was maintained at $1 \mathrm{~atm}$ with the Parrinello-Rahman barostat [40] and coupling constant of $5.0 \mathrm{ps}$. All initial systems were firstly equilibrated by the canonical ensemble (NVT) with velocity generation. Production trajectories were generated by NPT ensemble, and coordinates were saved every $10 \mathrm{ps}$ for analysis.

\section{Results}

The proliferation of human ES cells treated with venombased peptide $\mathrm{P} 13$

When venom-based peptide P13 was added to the E8 medium-cultured human ES cells, we found that it did not inhibit the growth of human ES cells but promoted the proliferation of human ES cells. After the human ES cells were grown in a 48-well culture dish for $24 \mathrm{~h}$, the human ES cells were dissociated. The cell counts were determined using a BD Accuri C6 flow cytometer. Using one-way analysis of variance (ANOVA), we found that the number of human ES cells that survived in the E8 medium with P13 was significantly higher than that of the human ES cells cultured only in the E8 medium (Fig. 1a).

\section{The activation of $p$-Erk1/2 and $p$-Smad2 in human ES cells treated with P13}

The human ES cells were cultured under three different culture conditions (E6, E6 + FGF2, and E8) and these conditions treated with P13 to observe the differences in the expressions of p-Erk1/2 (Fig. 1c, left); and under three different culture conditions (E6, E6 + TGF $\beta 1$, and E8) and these conditions treated with P13 to observe the differences in the expressions of p-Smad2 (Fig. 1d, right). Figure 1c (left) shows that the observed expression level of p-Erk1/2 was significantly upregulated in the E6 medium stimulated by P13 as compared to the E6 control medium. Compared to the human ES cells in the E6 + TGF $\beta 1$ medium, the expression level of p-Erk1/2 was upregulated in the E6 medium with P13 and/or FGF2. Compared to the human ES cells in the E8 medium, the expression level of $\mathrm{p}$-Erk1/2 was not significantly upregulated in the E8 medium with P13. Figure 1d (right) shows that the observed expression level of p-Smad2 was significantly upregulated in the E6 medium stimulated by P13 as compared to the E6 control medium. Compared to the human ES cells in the E6 + FGF2 medium, the expression level of p-Smad2 was upregulated in the E6 medium with P13 and/or TGF $\beta 1$. Compared to the human ES cells in the E8 medium, the expression level of $\mathrm{p}$-Smad2 was upregulated in the E8 medium with P13.

\section{The verification of human ES cells' self-renewal ability when treated with $\mathrm{P} 13$}

According to the preliminary results, four different media (E6, E6 + TGFß1, E6 + FGF2, and E8) were prepared, and peptide P13 was added to them; in total, eight different media were prepared. The human ES cells were serially passaged five times under eight different conditions to detect the differences in morphology and pluripotency. Figure $2 \mathrm{a}$ shows the observed morphological differences after five passages. The colony-forming characteristics of the human ES cells disappeared in the E6 and E6 + TGF $\beta 1$ media. However, the human ES cells still maintained their colony morphology under the E6 + P13 and E6 + TGF $\beta$ + P13 conditions after five passages. In the E6 + P13 medium, the human ES cells formed a 


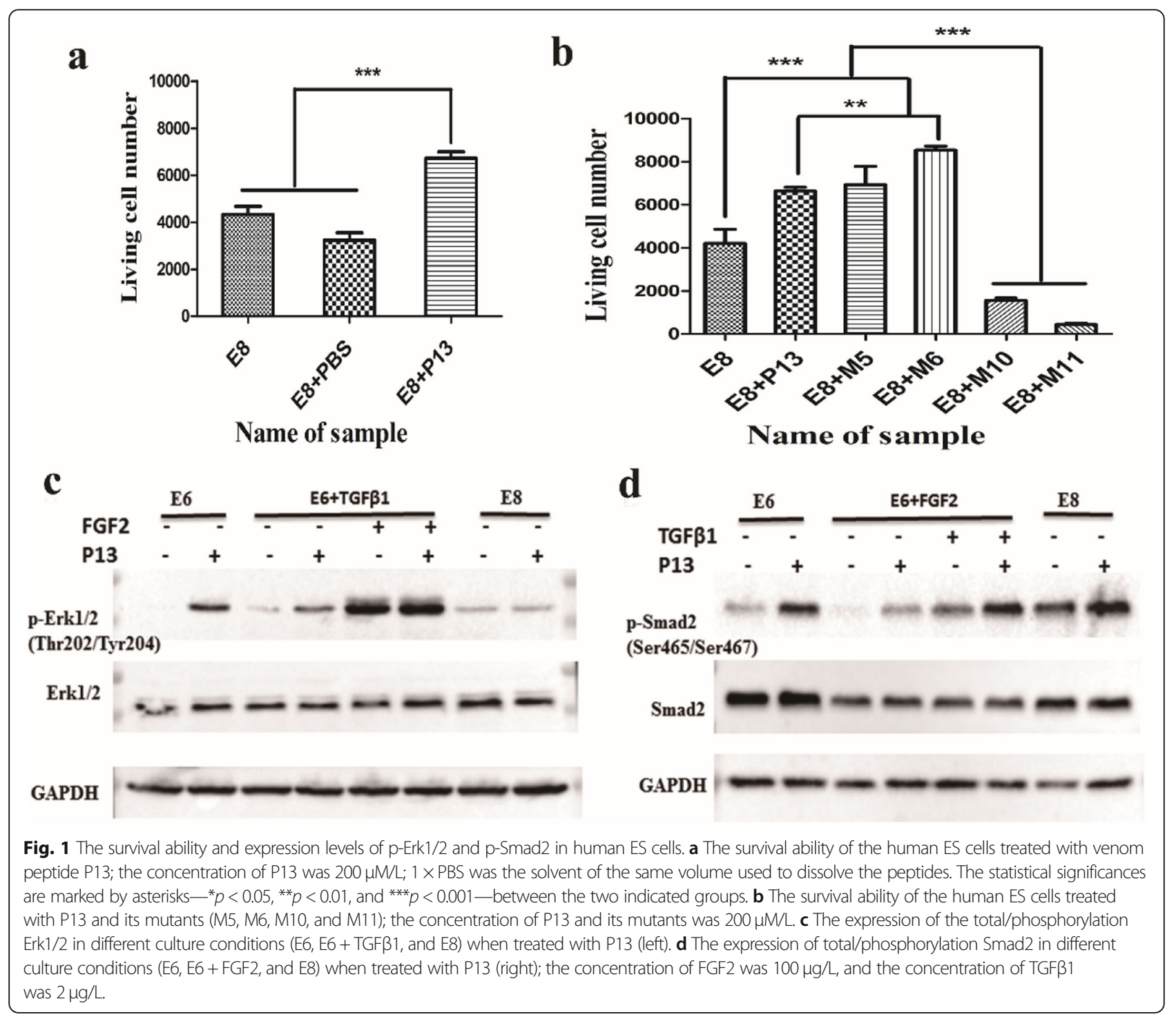

mixed state of colonies and dispersed cells. Then, when P13 was separately added to the E6 + FGF2 and E8 media, the human ES cells showed no significant differences in the morphology after continuous culture for five generations.

The quantitative polymerase chain reaction (qPCR) method was used to examine the self-renewal markers of human ES cells. The mRNA of OCT4, SOX2, and NANOG was examined for differential expressions under eight different conditions (Fig. 2b). Low mRNA expression levels of OCT4, SOX2, and NANOG were maintained in E6 and E6 + TGF $\beta 1$ as compared to the other conditions, which was consistent with the results we observed in the morphological Fig. 2a. Compared to the E6 and E6 + TGF 11 media, the OCT4, SOX2, and NANOG of the human ES cells were upregulated in the other six conditions. A one-way ANOVA $(* * * * 0<0.001)$ showed that the mRNA expression of NANOG was significantly upregulated compared to the E6 medium.

\section{The survival assay of $\mathrm{P} 13$ mutants}

The survival assay used to discover P13 was also used to screen for its mutants. When the amino acids at positions 12 and 13 were exchanged, the mutant P13-M5 (K12E/E13K) was obtained (Supplementary Table S1). The number of survival human ES cells in the E8 + M5 medium showed a slight increase, but there was no significant difference to the number of cells in the E8 + P13 medium. When the lysine at positions 13 and 14 in M5 was replaced by arginine, the mutant P13-M6 (K12E/ E13R/K14R) was obtained. A one-way ANOVA showed that the number of survival human ES cells in the E8 + M6 medium was significantly higher than those in the E8 + P13 medium (Fig. 1b). Concurrently, using the M6 


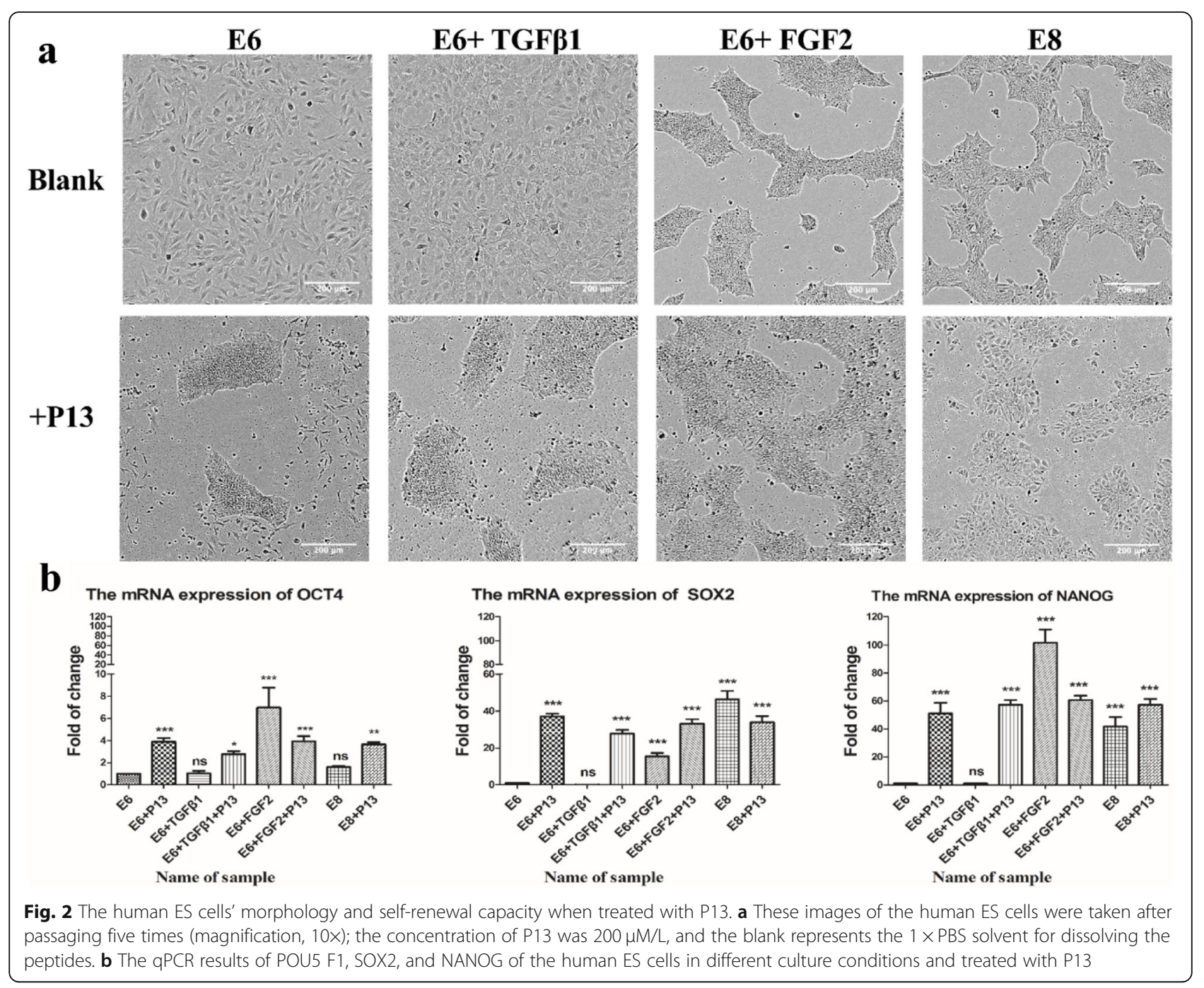

as a template, two key amino acids (cysteine and aspartic acid at the $\mathrm{N}$-terminus of P13) were also mutated to obtain two mutants, P13-M10 and P13-M11. Interestingly, the number of human ES cells that survived in the E8 + M10/M11 media was significantly lower than those in the E8 medium (Fig. 1b). The primary structure and molecular weight of P13 and its mutants are listed in Table S1.

The verification of the human ES cells' self-renewal ability when treated with M6

Based on the preliminary results, four different media (E6, E6 + TGF $\beta 1$, E6 + FGF2, and E8) were prepared, and peptide M6 (P13 as a control) was added to them as an additional component; then, twelve different media were prepared in total. The human ES cells were serially passaged five times under 12 different conditions to detect the differences in morphology and pluripotency. Figure 3a shows the morphological difference after five passages. The colony-forming characteristic of the human ES cells totally disappeared in the E6, E6 + P13, E6 + M6, and E6 + TGF $\beta$ media. However, the human ES cells maintained their colony-forming morphology in the E6 + TGF $\beta+\mathrm{P} 13$ and $\mathrm{E} 6+\mathrm{TGF} \beta+\mathrm{M} 6$ conditions after five passages compared to E6 + TGF $\beta$ medium. In the E6 + TGF $\beta+$ P13 and $\mathrm{E} 6+\mathrm{TGF} \beta+\mathrm{M} 6$ medium conditions, the human ES cells showed a mixed state of colonies and dispersed cells. P13 and M6 were then separately added to the E6 + FGF2 and E8 media, and the human ES cells showed no significant differences in their morphologies after five generations of continuous culture.

The qPCR assay was used to examine the self-renewal markers of human ES cells. The mRNA of OCT4, SOX2, and NANOG was examined for differential expression under 12 different conditions (Fig. 3b). Low mRNA expression levels of OCT4, SOX2, and NANOG were 


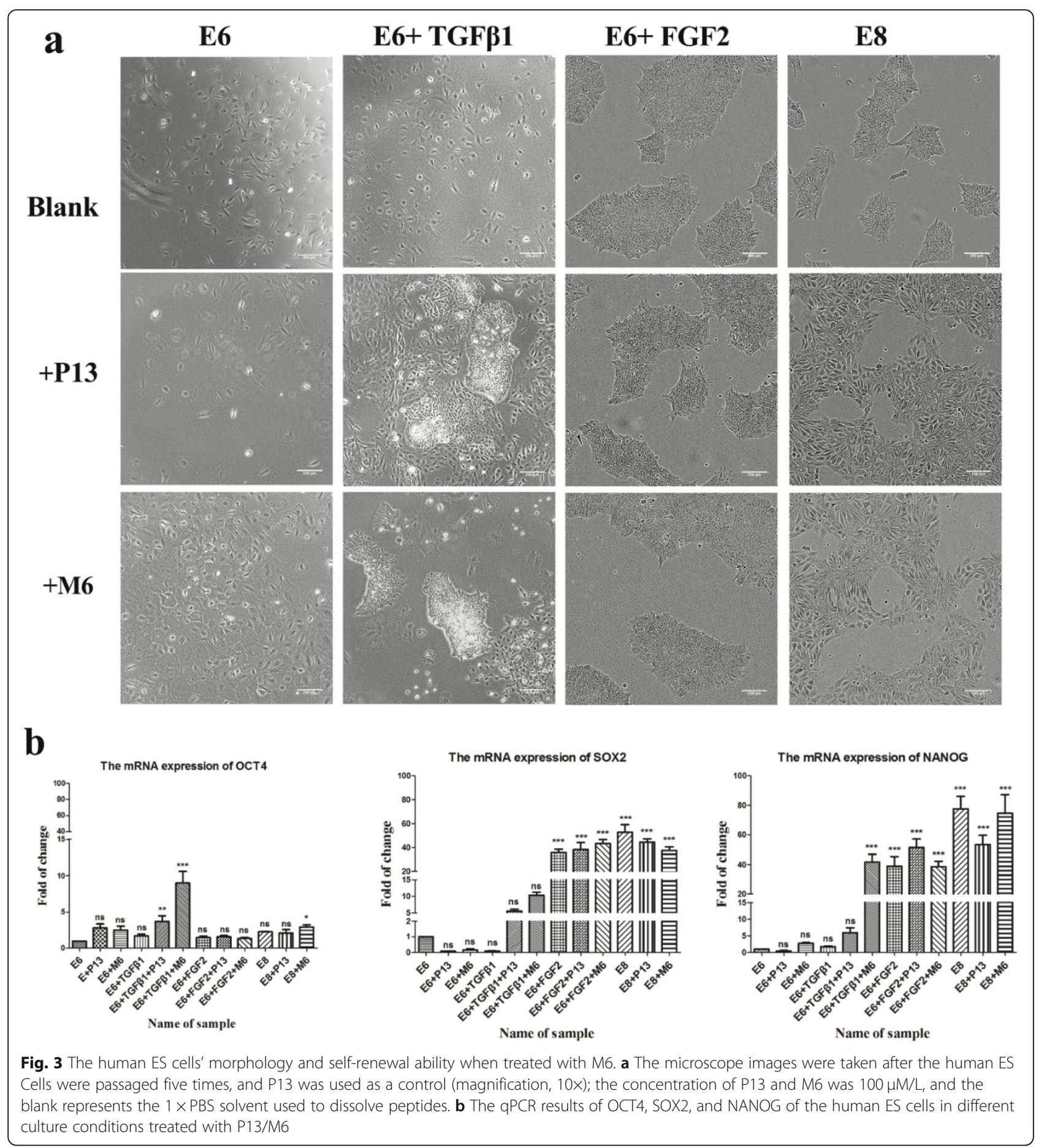

maintained in E6, E6 + P13, E6 + M6, and E6 + TGF $\beta 1$ as compared to the other conditions, which were consistent with the results observed in the above morphological Fig. 3a. Compared to the E6 + TGF $\beta 1$ medium, the OCT4, SOX2, and NANOG of the human ES cells were upregulated in the E6 + TGF $\beta 1+$ p13 and E6 + TGF $\beta 1+$ M6 conditions. A one-way ANOVA showed that the expression levels of SOX2 and NANOG were significantly upregulated in the $\mathrm{E} 6+\mathrm{FGF} 2, \mathrm{E} 6+\mathrm{FGF} 2+\mathrm{P} 13, \mathrm{E} 6+$ FGF2 + M6, E8, E8 + P13, and E8 + M6 media as compared to the E6 medium $(* * * 0<0.001)$.

\section{Localization of peptides in human ES cells to verify its cell-penetration ability}

Some short peptides can act as cell-penetrating peptides (CPPs) that penetrate cell membranes to perform their 
functions or serve as carriers to transport certain molecules into cells [41]. The purpose of this experiment was to determine whether P13 and M6 can enter cells to perform their respective functions. The human ES cells were treated with P13 and M6, each labeled by FITC fluorescence, for $24 \mathrm{~h}$, and the location of peptides was confirmed through confocal microscopy by the immunostaining of nuclear dye combined with cytoplasmic membrane dye. As can be seen in Fig. 4, the blue fluorescence represented the nucleus of the embryonic stem cells, red fluorescence represented the cell membrane, green fluorescence-labeled P13 and M6 were bound to the plasma membrane, and no green fluorescencelabeled P13 and M6 are found in the cytoplasm. This indicated that P13 and M6 do not belong to the CPP family.

\section{The validation of $p$-Erk $1 / 2$ and $p$-Smad 2 expression in} human ES cells treated with M6 without small molecular inhibitors

Based on the structural modification of P13 at the active site, we obtained a mutant, M6, with better proliferation activity. First, we compared the differences in the expression of p-Erk1/2 and p-Smad2 in the human ES cells stimulated by P13 and M6. Compared to the human ES cells in the E6 medium, the expression levels of p-Erk1/ 2 and p-Smad2 were significantly upregulated in the E6 medium with P13 and M6, respectively (Fig. 5a).
However, compared to the human ES cells in the E6 medium with P13, the expression levels of $\mathrm{p}$-Erk1/2 and p-Smad2 were not significantly upregulated in the E6 medium with M6.

\section{The molecular modeling of the receptor kinase domain} bound to a small molecular inhibitor

The PDB ID 3TZM represents the intracellular kinase domain of TGF $\beta$ receptor type 1 [27]. The 3TZM is actually a three-dimensional crystal structure that includes the small molecular inhibitor SB431542 and the TGF $\beta$ receptor. CDOCKER deleted the SB431542 and docked the A8301 into the FGFR intracellular kinase domain. The small molecular inhibitor A8301 bound the intracellular kinase domain binding pocket of TGF $\beta$ receptor type 1 (Fig. 6A). Figure 6A (c) shows a 2D model of the interaction between A8301 and TGF $\beta$ receptor type 1 in the active molecular window. The amino acids interacting with the receptor and ligand were labeled. The small molecule inhibitors bound to the kinase domain of the receptor, effectively inhibiting the phosphorylation of downstream molecules. The PDB ID 4WUN represents the intracellular kinase domain of FGFR1 [42]. A small molecular inhibitor, AZD4547, was bound to the binding pocket of the FGFR intracellular kinase domain (Fig. 6B). Figure $6 \mathrm{~B}(\mathrm{c})$ shows a $2 \mathrm{D}$ model of the interaction between AZD4547 and FGFR in the active molecular

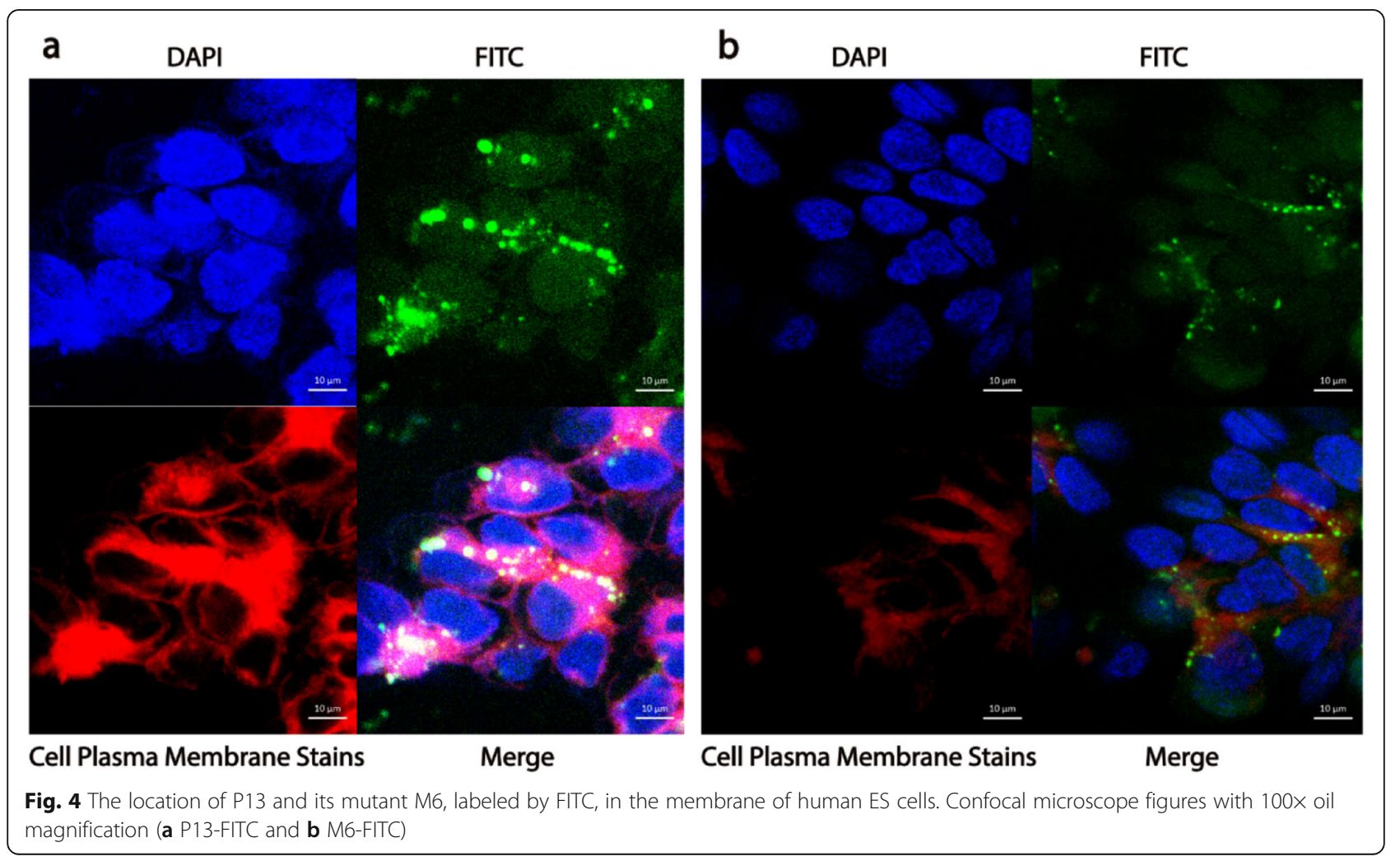




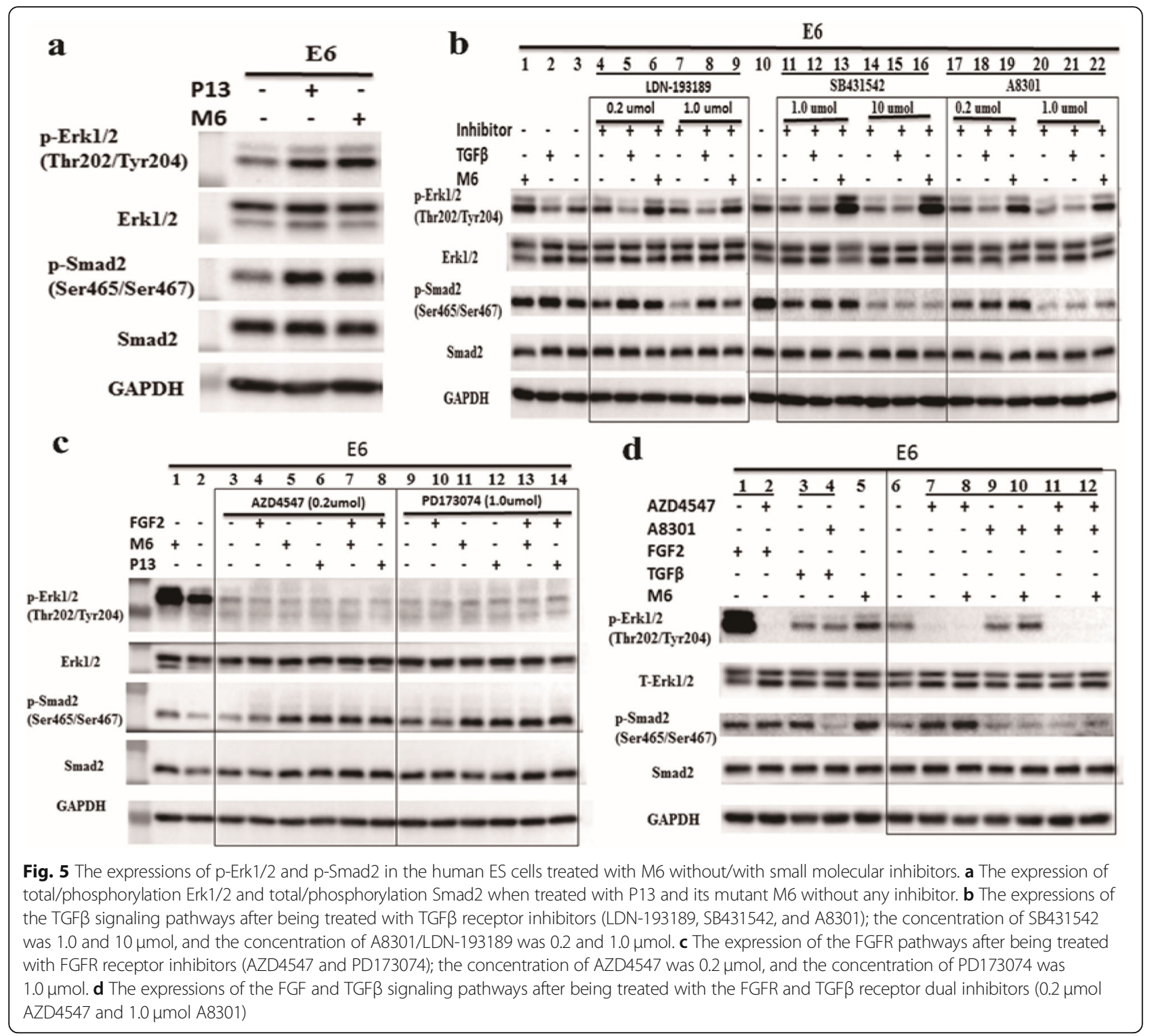

window, and the interacting amino acids between the receptor and ligand have been labeled.

The expression of $p$-Erk1/2 and $p-S m a d 2$ in human ES cells treated with M6 with small molecular inhibitors The human ES cells treated with TGF $\beta$ family receptor inhibitors LDN189193, SB431542, and A8301 to study the expression levels of p-Erk1/2 and p-Smad2. LDN193189 has the ability to inhibit ALK1 (ACVRL1), ALK2 (ACVR1A), ALK3 (BMPR1A), and ALK6 (BMPR1B) (IC50 $=0.8,0.8,5.3$, and $16.7 \mathrm{nM}$, respectively) and is a potent inhibitor of the bone morphogenetic (BMP) pathway [25]; SB431542 inhibits ALK4 (ACVR1B) and ALK5 (TGFBR1) $(\mathrm{IC} 50=140 \mathrm{nM}, 94 \mathrm{nM}$, respectively) and is a selective and potent inhibitor of the TGF- $\beta$ /Activin/NODAL pathway [26]. A8301 is a selective inhibitor of the type I activin/nodal receptor ALK4, TGF- $\beta$ type I receptor ALK5 kinase, and type I nodal receptor ALK7 (ACVR1C) (IC50 $=45,12$, and 7.5 $\mathrm{nM}$, respectively) $[27,28]$. As shown in the lanes 3-9 of Fig. 5b, $1.0 \mu \mathrm{mol}$ LDN189193 could inhibit the expression of p-Smad2 as compared to the control E6 medium (lane 3) and $0.2 \mu \mathrm{mol}$ LDN189193 could not inhibit the expression of $\mathrm{p}$-Smad2; however, compared to the stem cells in the E6 medium with $1.0 \mu \mathrm{mol}$ LDN189193, the expression of $\mathrm{p}$-Smad2 was upregulated in the respective E6 media treated with TGF $\beta$ and M6. Lanes 11-16 (SB431542) and 17-22 (A8301) show that $1.0 \mu \mathrm{mol}$ SB431542 and $0.2 \mu \mathrm{mol}$ A8301 could not inhibit the expression of $\mathrm{p}$-Smad2. However, a higher concentration of SB431542 $(10 \mu \mathrm{mol})$ and A8301 $(1.0 \mu \mathrm{mol})$ could significantly inhibit the expression of $\mathrm{p}$-Smad2; the 


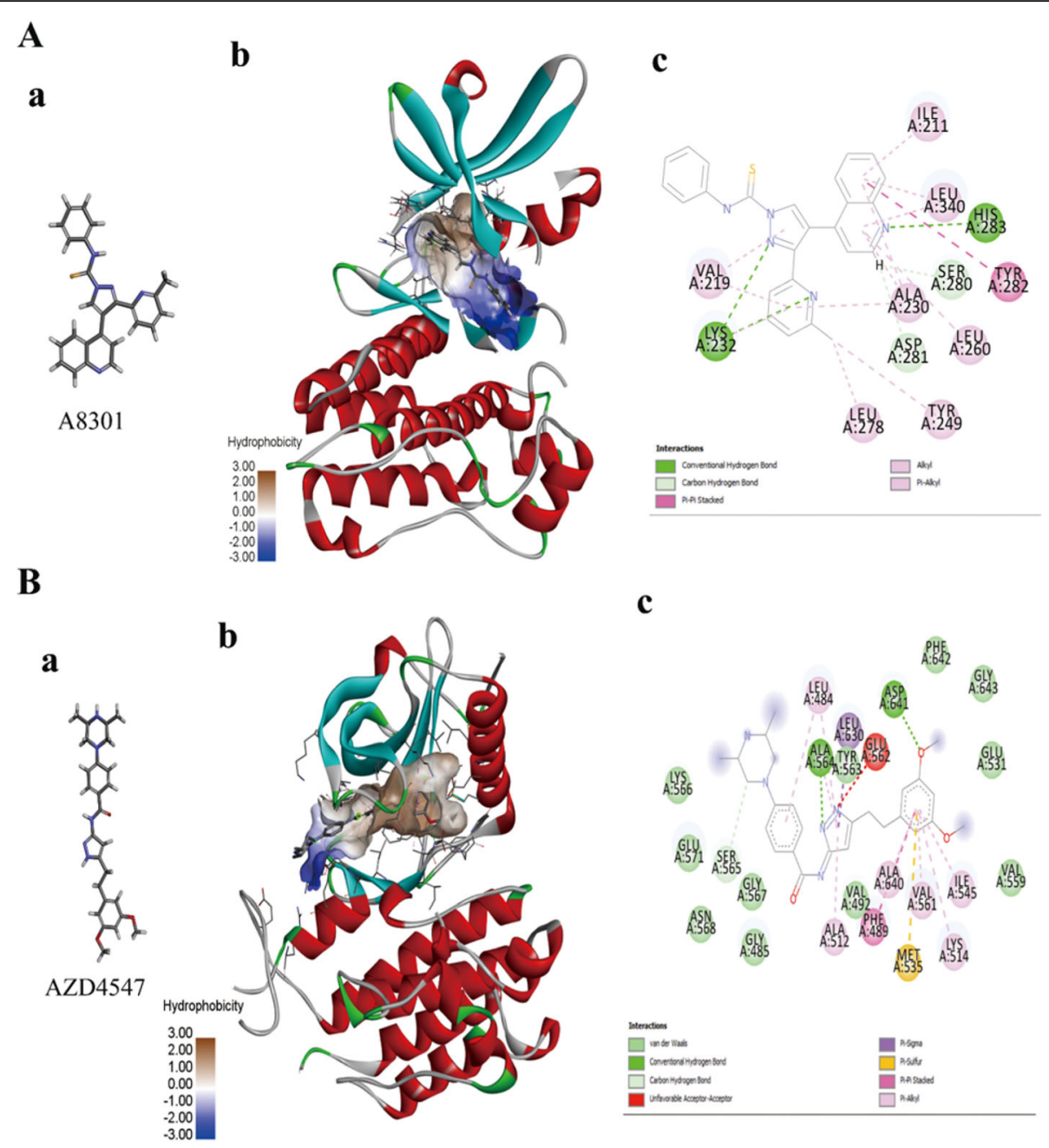

Fig. 6 The molecular modeling of the kinase domain treated with small molecular inhibitors. A The solid ribbon modeling of the FGFR kinase domain bound to AZD4547 based on the PDB ID 4WUN: (a) represents the 2D structure of AZD4547; (b) represents the AZD4547 bound to the pocket of the FGFR intracellular kinase domain; and (c) is a 2D model of the interaction between AZD4547 and FGFR in the active molecular window. B The solid ribbon modeling of the TGF $\beta$ receptor kinase domain bound to A8301 based on the PDB ID 3TZM: (a) represents the 2D structure of A8301; (b) shows the A8301 bound to the pocket of the TGF $\beta$ receptor intracellular kinase domain; and (c) is a 2D model of the interaction between $\mathrm{A} 8301$ and TGF $\beta$ in the active molecular window

expression of p-Erk1/2 was upregulated in the E6 medium with M6, but the upregulated expression of $\mathrm{p}$ Erk1/2 could not be observed in the E6 medium with TGF $\beta$.

The human ES cells were treated with FGF family receptor inhibitors AZD4547 and PD173074 to observe the expression levels of $\mathrm{p}$-Erk1/2 and $\mathrm{p}$-Smad2. AZD4547 [23] is a strong FGFR1/2/3 inhibitor (IC50 = $0.2,2.5$, and $1.8 \mathrm{nM}$, respectively) with weaker activity against FGFR4. Docetaxel (AZD4547) has entered a phase II/III trial to treat patients with stage IV squamous cell lung cancer (https://clinicaltrials.gov). PD173074 is a potent FGFR1 inhibitor (IC50 $=25 \mathrm{nM}$ ) in cell-free assays [24]. Lanes $2-8$ in Fig. $5 \mathrm{c}$ show that $0.2 \mu \mathrm{mol}$ AZD4547 could inhibit the expression of p-Erk1/2 compared to the control E6 medium (lane 2) and the E6 media treated with P13, M6, and/or FGF2. However, the expression of p-Smad2 was upregulated in the E6 media treated with P13, P13 + FGF2, M6, and M6 + FGF2 as compared to the control E6 medium and E6 medium with $0.2 \mu \mathrm{mol}$ AZD4547. Lanes 9-14 in Fig. 5c show that $1.0 \mu \mathrm{mol}$ PD173074 could inhibit the expression of pErk1/2 as compared to the control E6 medium and the E6 media with P13, M6, and/or FGF2. However, the expression of $\mathrm{p}-\mathrm{Smad} 2$ was upregulated in the E6 media with P13, P13 + FGF2, M6, and M6 + FGF2 as compared to the control E6 medium and E6 medium with $1.0 \mu \mathrm{mol}$ PD173074.

The human ES cells were treated with the FGF receptor inhibitor AZD4547 $(0.2 \mu \mathrm{mol})$ and/or TGF $\beta$ receptor 
inhibitor A8301 $(1.0 \mu \mathrm{mol})$ to study the expression of pErk1/2 and p-Smad2, as shown in Fig. 5d. The lanes 1-2 validate the function of the FGF2 and FGF receptor inhibitor AZD4547; FGF2 upregulated the expression of pErk1/2, and AZD4547 inhibited the expression of pErk1/2, even in the E6 medium with FGF2. The lanes 34 validate the function of the TGF $\beta 1$ and TGF $\beta$ receptor inhibitor A8301; TGF $\beta 1$ upregulated the expression of p-Smad2, and A8301 inhibited the expression of pSmad2, even in the E6 medium with TGF $\beta 1$. The lanes 7-10 validated the expression difference between $p$ Erk1/2 and p-Smad2 in the single and double inhibitors (FGF and TGF $\beta$ ) of the human ES cells treated with M6. The lanes 7-8 show that the expression of $\mathrm{p}$-Erk1/2 was inhibited by $0.2 \mu \mathrm{mol}$ AZD4547, even in the E6 medium with M6, and the lanes 9-10 show that the expression of p-Smad2 was inhibited by $1.0 \mu \mathrm{mol} \mathrm{A8301,} \mathrm{even} \mathrm{in} \mathrm{the}$ E6 medium with M6. However, the lanes 11-12 show that the expressions of $\mathrm{p}$-Erk $1 / 2$ and $\mathrm{p}$-Smad2 were inhibited by the dual-inhibitors $0.2 \mu \mathrm{mol}$ AZD4547 and $1.0 \mu \mathrm{mol}$ A8301, even in the E6 medium with M6.

\section{Molecular dynamics (MD) simulations}

Our biological experimental results suggest that both P13 and M6 are promising alternatives to FGF for activating the FGFR protein and inducing the intracellular downstream signaling with the latter exhibited better proliferation activity. To understand the biological function of the two peptides at the molecular level, we modeled peptide binding with the 2:2 FGFR:HS complex by classical MD simulations. Twenty chains of peptides were added to the solvent phase of the system and allowed to equilibrate around the protein complex. Structures and dynamics of the protein complex in the presence of peptides were analyzed and compared to the native 2:2:2 FGF:FGFR:HS (FGF-bound) and apo 2:2 FGFR:HS (FGF-free) complexes. Figure 7 shows the initial and final snapshots of the 500-ns simulations of four types of systems. As clearly seen, multiple peptides are associated with the complex in both the upper D2 and lower D3 domains of the receptor. M6 appears to bind more strongly and tightly with the complex while P13 exhibits looser binding with frequent attachment and detachment events in the course of a simulation. To determine factors to the peptide binding, we computed the non-bonded interaction energies between the peptide and complex from the Coulombic and Lennard-Jones potentials. As shown in Supplementary Fig. S3, the binding of the peptide to the complex is dominantly driven by electrostatic interactions. A comparison of the energy

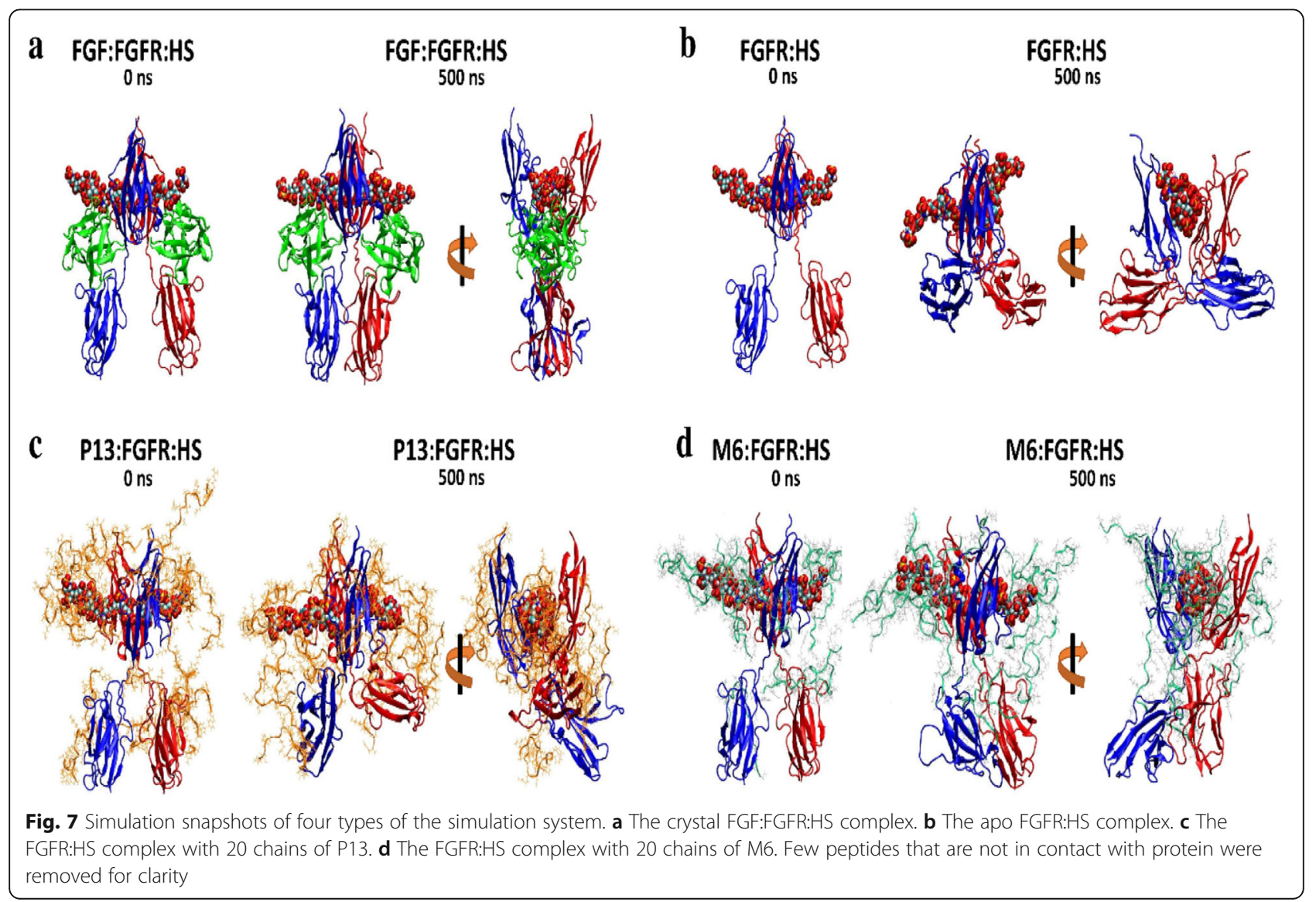


values of M6 to those of P13, we see that there are pronounced electrostatics and van der Waals interactions of HS-peptide $(\mathrm{dE}=-774.6$ and $-109.2 \mathrm{~kJ} / \mathrm{mol}$, respectively). On the other hand, P13 shows stronger binding to the protein in electrostatic interaction $(\mathrm{dE}=-441.9 \mathrm{~kJ} /$ $\mathrm{mol}$ ). The total non-bonded interaction energy of M6 is $-8142.2 \mathrm{~kJ} / \mathrm{mol}$ compared to $\mathrm{P} 13$ of $-7690.3 \mathrm{~kJ} / \mathrm{mol}$, which gives a difference of $-451.9 \mathrm{~kJ} / \mathrm{mol}$.

Consequently, the differential bindings of M6 and P13 to the complex induced different changes in the structure of the complex. With M6, the structure of the FGFR:HS complex resembles the equilibrated FGFbound structure where the D2 and D3 domains are stretched and the D3 domains of the two chains stay in the proximal distance. In contrast, with P13, the structure of the FGFR:HS complex resembles closer to the equilibrated FGF-free structure that it has undergone a large conformational change to adopt a strikingly different fold upon the loss of its native ligand. A comparison of the root-mean-squared deviation (RMSD) and D3 separation distance in Fig. 8a and b reveal that the change in the complex structures of both P13 and M6 occurred almost immediately but the changed structures reached stability at $300 \mathrm{~ns}$. The close interactions of the
D3 domains in both P13 and M6 are stable, though in a slightly larger separation distance (center of mass of the two domains is approx. $3 \mathrm{~nm}$ versus $2 \mathrm{~nm}$ in the equilibrated FGF-bound state of the crystal simulation). This discovery is consistent with the result that D3 of the activated two FGF receptors gets closer by using the FRET-based technique [43].

We further analyzed the conformational change of the complex in the course of simulation by principal component analysis (PCA). We concatenated the four simulation trajectories to be compared, namely FGF-bound, FGF-free, P13, and M6, and computed the covariance matrix of positional fluctuations of protein backbone atoms. The matrix was diagonalized; the eigenvectors and associated eigenvalues representing the axes of atomic motions and mean square fluctuations along these axes were obtained. Figure $8 \mathrm{c}$ shows the 2dimensional projection of the simulation trajectories onto the first and second PCA modes, axes of the largest and second-largest atomic motions of the protein. The result of PCA analysis shows that the conformational change of the protein from the initial state to the active state (equilibrated FGF-bound form) involves only shortdistance atom movement whereas the change to the
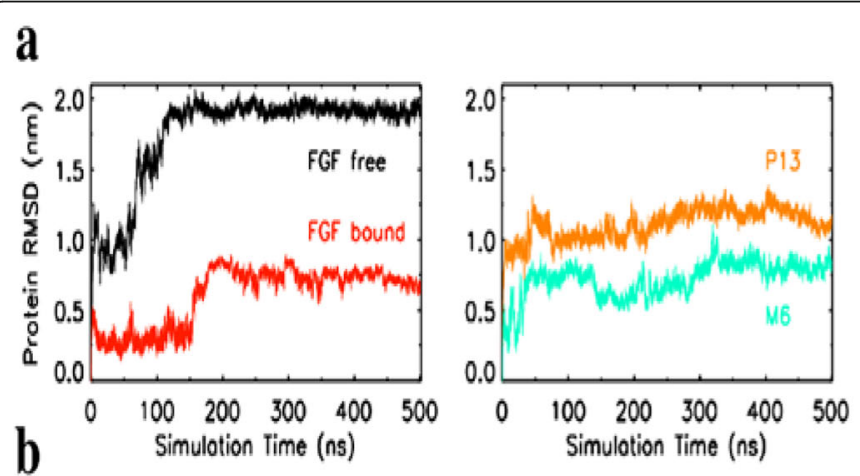

c
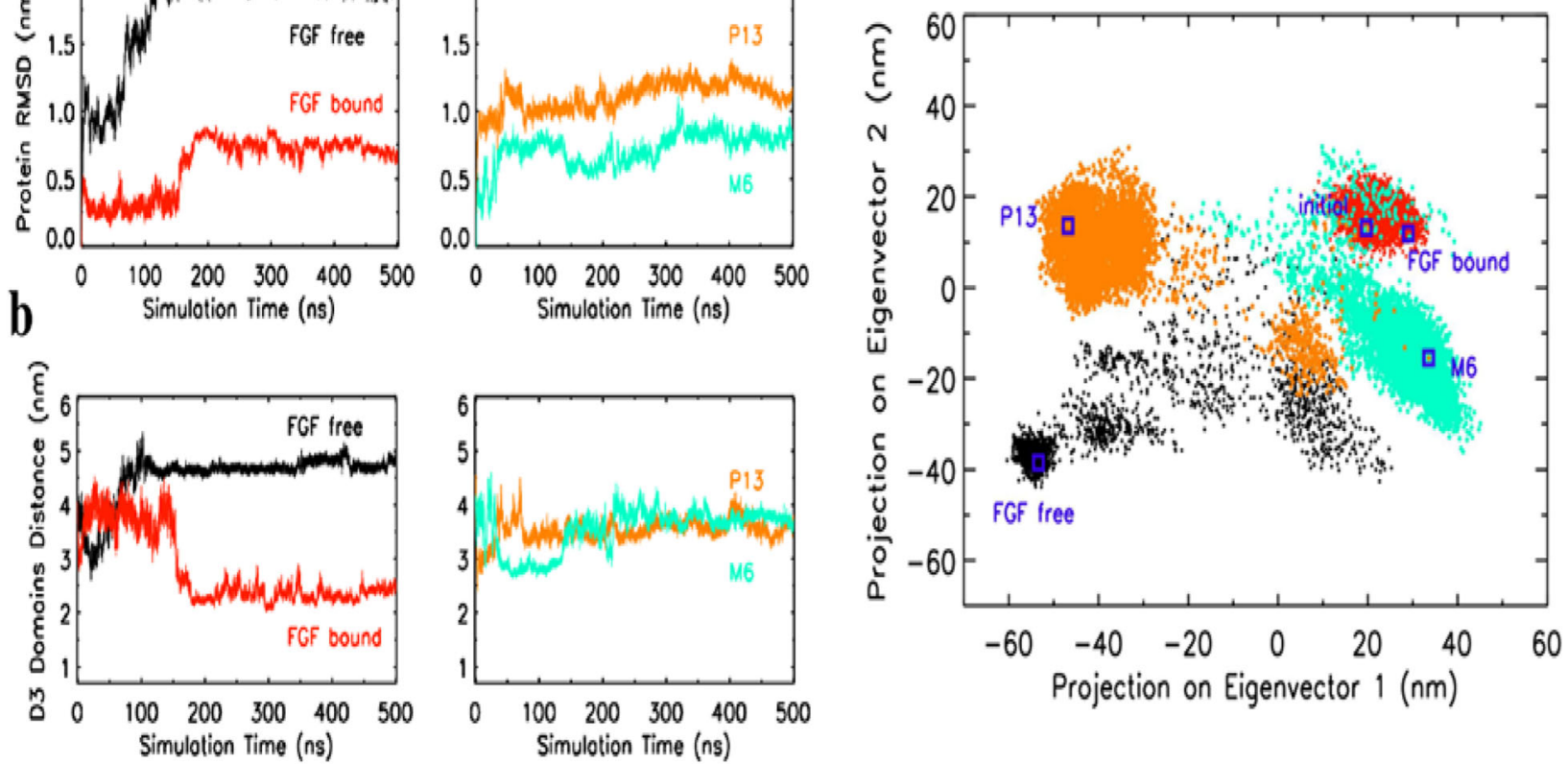

Fig. 8 Analysis of structural changes of FGFR under different ligand conditions: FGF-free, FGF-bound, P13, and M6. a The root-mean-squared deviation (RMSD) of the protein backbone in reference to its initial structure. $\mathbf{b}$ The center-of-mass separation distance between the D3 domains of the two FGFR chains. c Two-dimensional projection of the four combined trajectories (FGF-free, FGF-bound, P13, and M6) on the first and second PCA modes computed from the coordinates of FGFR backbone atoms. The square symbols indicate positions of protein conformations in terms of PCA coordinates for the initial (all trajectories have the same initial protein conformation) and the final state (500 ns) of each trajectory. Color codes for trajectory: FGFbound (red), FGF-free (black), P13 (orange), M6 (cyan) 
inactive state (equilibrated FGF-free form) involves large-scale motion corresponding to the closing action of the D2-D3 domains of the two chains. The projection data reveals that upon binding of M6 peptides, the protein maintained similar conformational states as the initial and FGF-bound forms for some time, then it switched to a conformational state that is close to the FGF-bound form. Interestingly, with P13, the protein underwent relatively larger motion to settle on conformational states that are intermediary between the initial and FGF-free states.

\section{Discussion}

Self-renewal is the process of cell division with the maintenance of pluripotency and is enabled to eliminate the differentiation-inducing signal of mitogen-activated protein kinase [44]. The Erk $1 / 2$ signaling stimulated by FGFs and the SMAD2/3 signaling stimulated by TGF $\beta$ are critical for the maintenance of the stem cell selfrenewal ability $[12,45]$. The crystal structure of FGF2 binding the extracellular region of FGFR was first determined at $2.8 \AA$ resolution in 1999 [46]. The same research group analyzed the crystal structure of a ternary FGF-FGFR-Heparin complex (PDB ID: 1FQ9) in the second year and discussed a dual role of heparin [30]. Subsequent mutation analysis and related experimental evidence further prove the rationality of the 1FQ9 crystal structure $[47,48]$. Therefore, this study used 1FQ9 as a template for molecular dynamics analysis. In 2008, the crystal structure of two molecules of TGF $\beta 3$ bound to heterotetrameric TGF $\beta$ RI/ TGF $\beta$ RII (2PJY) was determined at $3.0 \AA$ resolution [49]. However, the crystal structure of TGF $\beta$ bound to the corresponding receptor is a complicated heterotetramer, which leads to relatively few studies so far, and more experimental evidence is needed to prove its crystal structure rationality. How do the 18AA short toxin peptide P13 and M6 play a similar role in FGF2 (16.4 kDa) and TGF $\beta 1$ (25.6 kDa disulfidelinked homodimer)? We try to discuss this question by exploring the activation mechanisms of their corresponding receptors.

Fibroblast growth factor receptors (FGFRs) are transmembrane proteins composed of three domains: an extracellular ligand-binding region, a single transmembrane portion, and an intracellular kinase domain [50] (Fig. 9a and Supplementary Fig. S4). The extracellular region consists of three immunoglobulin-like regions: D1, D2, and D3. An acid box (AB) exists between the $\mathrm{D} 1$ and $\mathrm{D} 2$ regions. The D1 and acid box play key roles in the self-regulation of FGFR molecules, and D2 and D3 are ligand-binding regions [47]. Kinase domain phosphorylates downstream molecules and can be inhibited by small-molecule inhibitors such as AZD4547 and PD173074. The D2 region includes a heparin-binding site. FGFRs have their own set of intramolecular regulatory mechanisms-“autoinhibition" (Fig. 9b) [51]. D1 competitively binds to a ligand-binding site formed by D2 and D3. At the same time, the acid box binds to the positively charged "canyon" within the same receptor, which is also the heparin-binding site (18AA in FGFR1:

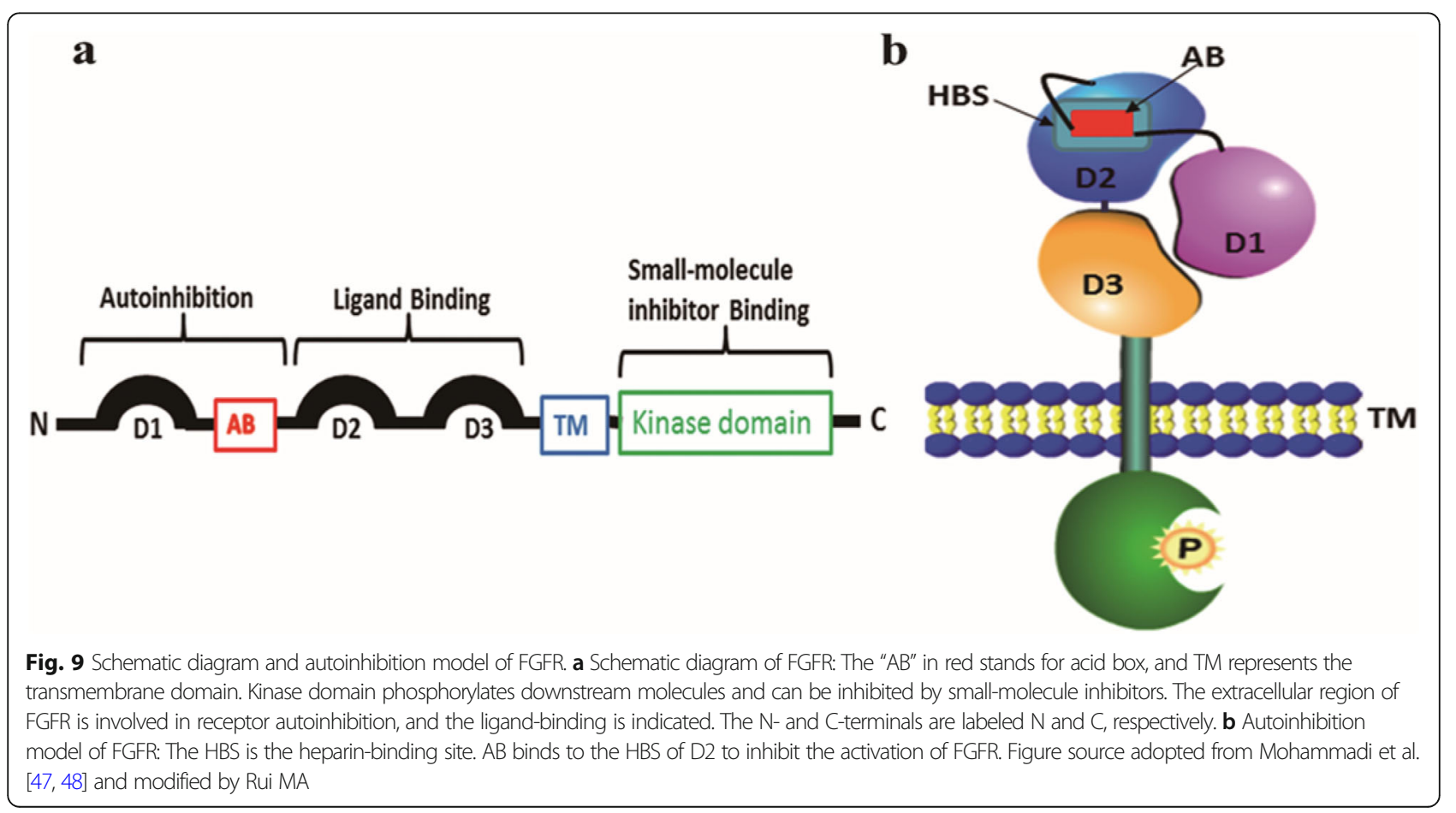


KMEKKLHAVPAAKTVKFK (six lysine residues) and 18AA in FGFR2: KMEKRLHAVPAANTVKFR (three lysine residues and two arginine residues)) (Supplementary Fig. S4) [46]. When D1 and the acid box occupy their intramolecular binding sites, the FGFR monomer adopts a "closed" and auto-inhibited configuration; however, when FGF and heparan sulfate proteoglycans (HSPGs) individually compete for the ligand-binding site and acid box, the FGFR in the closed configuration is opened and activated. From the above-unbiased evidence, we speculated that venom peptides P13 (18AA: WCYKLPDRVSIKEKGRCN (three lysine residues and two arginine residues)) and its mutant M6 (18AA: WCYKLPDRVSIERRGRCN (one lysine residues and four arginine residues)) have the ability to compete for the acid box to relieve the autoinhibition of FGFR.

An X-ray crystal structure of a dimeric complex (PDB ID: 1FQ9) confirmed two essential prerequisites for FGFR activation: the involvement of two molecules of FGFR that become dimers and two molecules of heparins [30]. The molecules involved in FGFR activation were heparan sulfate proteoglycans (HSPGs) on the cell membrane, and the two heparins used in the crystal were only convenient for crystallization in vitro [22, 52]. The X-ray crystal structure included the extracellular regions of FGFR1, FGF2, and heparin in a 2:2:2 ratio [30]. The heparin simultaneously bound two FGF2 ligands and two FGFR1 receptor molecules in the 3D structure. Taking this ternary crystal complex as the template, we performed MD simulations to study the energetics and dynamics of multiple peptide binding to the FGFR protein complex. A batch of 20 chains of P13 or M6 peptides were allowed to equilibrate around the 2:2 FGFR: HS complex with the FGF removed. During the equilibration where the complex was positionally restrained, the peptides were observed to quickly bind to the complex due to their strong electrostatic attractions with FGFR and HS molecules. Subsequently, in the classical MD simulations following the equilibration, the protein complex underwent different conformational changes induced by the bound P13 or M6 peptides. To try to understand the effects of these conformational changes on the biological function of FGFR, we compared the peptide simulations to the FGF-bound (native) and FGFfree (apo) simulations of the complex. Our simulations reveal that the conformations of the FGF-bound and FGF-free forms of the complex are different dramatically. The FGF-bound complex in equilibrium resembles its crystal structure where the D2 and D3 domains are stretched, the two HS molecules bind tight to both D2 and FGF, and importantly, the two D3 domains are bound together. The closer proximity of the D3 domains suggests that the complex structure is in its active state, in agreement with the FRET-based experimental result
[43]. In contrast, in the apo simulation, the FGFR:HS complex, losing the FGF ligand, undergoes a large hinge motion by moving the lower D3 domain of an FGFR chain towards the upper D2 domain of the opposite FGFR chain. This motion occurred spontaneously and was completed within a short simulation time of $200 \mathrm{~ns}$. Thereafter, the FGF binding site remains partially closed. The native and apo simulations reveal that the D2-D3 conformations and D3-D3 domain contact are distinct for the activated FGFR and its inactivated counterpart.

We compared the structural changes and energetics of the FGFR:HS complex upon binding of P13 and M6 in the peptide simulations to the native and apo simulations. The RMSD and PCA results suggest that both peptides have the capability to maintain conformation of the complex to some intermediate forms between the active and inactive states of FGFR. Importantly, both peptides entail closer domain-domain contact of D3 that might be crucial to the signal transduction function of FGFR. It is noteworthy that the structure of the M6bound FGFR resembles closer to the activated FGFR compared to P13 presumably due to its higher affinity to the FGFR:HS complex. Hence, the computational results provide some insights on the peptide-binding modes of P13 and M6 to FGFR and support the better proliferation activity of M6 that is concluded from our biological experiments.

The TGF $\beta$ receptors are a family of Ser/Thr kinase receptors involved in the TGF $\beta$ signaling pathway, and over thirty members determine their multifunctional nature [15]. The main functions of the TGF $\beta$ receptors include self-renewal of embryonic stem cells, gastrulation, differentiation, organ morphogenesis, and adult tissue homeostasis. The TGF $\beta$ superfamily receptors send signals to a family of intracellular Smad protein kinases that are further passed into the nucleus to regulate the expression of related genes [53]. The activation mechanism of the TGF $\beta$ receptor can be divided into three parts [54] (Supplementary Fig. S5). First, TGF $\beta$ directly binds to a constitutively active kinase TGF $\beta$ receptor II; second, TGF $\beta$ is recognized by receptor I, and receptor II recruits receptor I to form a tetramer complex; and third, TGF $\beta$ receptor II phosphorylates receptor I and then transmits the signal to the downstream substrate. An in-depth study of the TGF $\beta$ receptor activation process revealed that glycoproteins anchored on the cell membrane are involved in the activation process, including the membrane-anchored Betaglycan and Endoglin, and facilitate ligand-binding to the TGF $\beta$ receptors [55-57].

The extracellular structure of the TGF $\beta$ receptor possesses a similar structure to the three-finger toxin [58], and the extracellular structure of FGFR has immunoglobulin-like scaffolds [47]. Although there are some differences between the extracellular structures of 
these two receptors, one of the common features is the participation of extracellular proteoglycans with separate domains when the signaling pathway is activated [20, 57, 59]. The activation pattern of FGFR is to "pull/drag" the two monomers receptors into a dimer, and the activation mode of the TGF $\beta$ receptor is to dimerize a TGF $\beta$ receptor II homodimer and a TGF $\beta$ receptor I homodimer into a heterotetramer that can activate the downstream signaling pathway. Therefore, we hypothesized that any molecule has the ability to dimerize the FGFR and TGF $\beta$ receptors and activate their corresponding signaling pathways. So we speculate that underlying molecular mechanisms of venom peptide P13 and its mutant M6 have a higher affinity to heparan sulfate and the ability to synergize proteoglycans to activate the TGF and FGF signaling pathways.

After millions of years of evolution, venom peptides and other molecules originating from venom studied till date have resulted in a diverse and versatile drug library for further development and their utilization against diseases, including exenatide (type 2 diabetes mellitus drug), captopril (hypertension drug), and hemocoagulase (for the treatment of prophylaxis and hemorrhages during surgery) [60].

\section{Conclusions}

This study served to broaden the overall understanding of the versatility of toxin peptides and provide more ideas on optimizing the best culture media condition(s) for culturing human stem cells. To the best of our knowledge, P13 (or its potent mutant M6) reported in this study is the first venom-based peptide that can work on the FGF and TGF- $\beta$ signaling pathways to promote the self-renewal capability of hESCs.

\section{Supplementary information}

Supplementary information accompanies this paper at https://doi.org/10. 1186/s13287-020-01766-9.

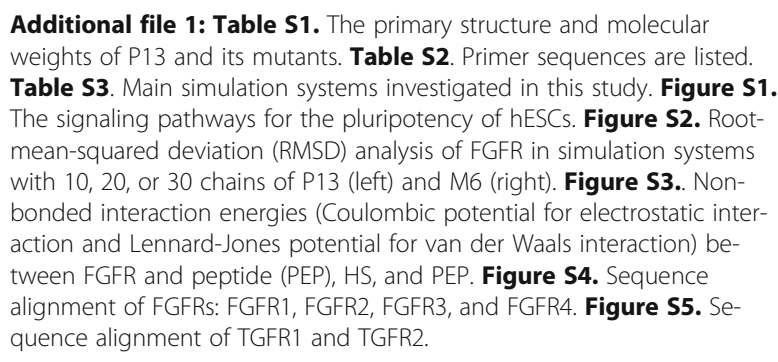

\section{Abbreviations}

hESCs: Human embryonic stem cells; hPSCs: Human pluripotent stem cells; iPS cells: Induced pluripotent stem cells; E8: Essential 8тм; ANOVA: One-way analysis of variance; qPCR: Quantitative polymerase chain reaction; CPP: Cellpenetrating peptide; FGFRs: Fibroblast growth factor receptors; HSPGs: Heparan sulfate proteoglycans; TGF 3 : Transforming Growth Factor beta

\section{Acknowledgements}

All simulations were performed at the High-Performance Computing Cluster (HPCC) provided by the Information and Communication Technology Office (ICTO) of the University of Macau. Thanks to Ms. Ema Zivkovic for proofreading the manuscript. The authors would also like to thank Ms. Sin Wa Wong from the Bioimaging \& Stem Cell Core Facility at the Faculty of Health Sciences University of Macau for providing technical support on the live cell and confocal imaging analysis.

\section{Authors' contributions}

Rui MA and Zhili REN carried out the experiments, while Rui MA, Bin LI, Guokai CHEN, and Hang Fai KWOK designed the experiment; Shirley W. I. Siu and Rui MA analyzed and constructed the calculation model; Rui MA, Shirley W. I. Siu, and Hang Fai KWOK drafted and revised the manuscript. All authors read and approved the final manuscript.

\section{Funding}

This research was funded by the Science and Technology Development Fund, Macau SAR (File no. 019/2017/A1).

\section{Availability of data and materials}

All data generated or analyzed during this study are included in this published article (and its supplementary information files).

Ethics approval and consent to participate

Not applicable.

\section{Consent for publication}

Not applicable.

\section{Competing interests}

The authors declare no conflict of interest.

\section{Author details}

'Institute of Translational Medicine, Faculty of Health Sciences, University of Macau, Avenida de Universidade, Taipa, Macau SAR. ${ }^{2}$ Cancer Centre, Faculty of Health Sciences, University of Macau, Avenida de Universidade, Taipa, Macau SAR. ${ }^{3}$ Centre of Reproduction, Development \& Aging, Faculty of Health Sciences, University of Macau, Avenida de Universidade, Taipa, Macau SAR. ${ }^{4}$ Department of Computer and Information Science, Faculty of Science and Technology University of Macau, Avenida de Universidade, Taipa, Macau SAR.

Received: 17 February 2020 Revised: 29 May 2020

Accepted: 8 June 2020 Published online: 18 June 2020

\section{References}

1. King GF. Venoms as a platform for human drugs: translating toxins into therapeutics. Expert Opin Biol Ther. 2011;11(11):1469-84.

2. Ma R, Mahadevappa R, Kwok HF. Venom-based peptide therapy: insights into anti-cancer mechanism. Oncotarget. 2017;8(59):100908-30.

3. Li B, Lyu P, Xi XP, Ge LL, Mahadevappa R, Shaw C, Kwok HF. Triggering of cancer cell cycle arrest by a novel scorpion venom-derived peptideGonearrestide. J Cell Mol Med. 2018;22(9):4460-73.

4. King GF, Escoubas P, Nicholson GM. Peptide toxins that selectively target insect Na-V and Ca-V channels. Channels. 2008;2(2):100-16.

5. de la Vega RC R, Possani LD. Overview of scorpion toxins specific for $\mathrm{Na}$ + channels and related peptides: biodiversity, structure-function relationships and evolution. Toxicon. 2005;46(8):831-44.

6. Dutertre S, Lewis RJ. Use of venom peptides to probe ion channel structure and function. J Biol Chem. 2010;285(18):13315-20.

7. Evans MJ, Kaufman MH. Establishment in culture of pluripotential cells from mouse embryos. Nature. 1981;292(5819):154-6.

8. Thomson JA, Itskovitz-Eldor J, Shapiro SS, Waknitz MA, Swiergiel JJ, Marshall VS, Jones JM. Embryonic stem cell lines derived from human blastocysts. Science. 1998;282(5391):1145-7.

9. Castelvecchi D. How human embryonic stem cells sparked a revolution (vol 555, pg 428, 2018). Nature. 2018;557(7703):18.

10. He SH, Nakada D, Morrison SJ. Mechanisms of stem cell self-renewal. In: Annual Review of Cell and Developmental Biology vol 25; 2009. p. 377-406. 
11. Akopian V, Andrews PW, Beil S, Benvenisty N, Brehm J, Christie M, Ford A, Fox V, Gokhale PJ, Healy L, et al. Comparison of defined culture systems for feeder cell free propagation of human embryonic stem cells. In Vitro Cell Dev Biol Anim. 2010;46(3-4):247-58.

12. Chen GK, Gulbranson DR, Hou ZG, Bolin JM, Ruotti V, Probasco MD, SmugaOtto K, Howden SE, Diol NR, Propson NE, et al. Chemically defined conditions for human iPSC derivation and culture. Nat Methods. 2011;8(5): 424-U476.

13. Ludwig TE, Bergendahl V, Levenstein ME, Yu JY, Probasco MD, Thomson JA. Feeder-independent culture of human embryonic stem cells. Nat Methods. 2006:3(8):637-46.

14. Xu RH, Sampsell-Barron TL, Gu F, Root S, Peck RM, Pan GJ, Yu JY, Antosiewicz-Bourget J, Tian SL, Stewart R, et al. NANOG is a direct target of TGF beta/Activin-mediated SMAD signaling in human ESCs. Cell Stem Cell. 2008;3(2):196-206.

15. Massague J. TGFbeta signalling in context. Nat Rev Mol Cell Biol. 2012; 13(10):616-30

16. Vallier L, Alexander M, Pedersen RA. Activin/Nodal and FGF pathways cooperate to maintain pluripotency of human embryonic stem cells. J Cell Sci. 2005;118(19):4495-509.

17. Young RA. Control of the embryonic stem cell state. Cell. 2011;144(6):940-54.

18. Beers J, Gulbranson DR, George N, Siniscalchi LI, Jones J, Thomson JA, Chen G. Passaging and colony expansion of human pluripotent stem cells by enzyme-free dissociation in chemically defined culture conditions. Nat Protoc. 2012;7(11):2029-40.

19. Cardin AD, Weintraub HJ. Molecular modeling of protein-glycosaminoglycan interactions. Arteriosclerosis. 1989;9(1):21-32

20. Hileman RE, Fromm JR, Weiler JM, Linhardt RJ. Glycosaminoglycan-protein interactions: definition of consensus sites in glycosaminoglycan binding proteins. Bioessays. 1998;20(2):156-67.

21. Fromm JR, Hileman RE, Caldwell EEO, Weiler JM, Linhardt RJ. Pattern and spacing of basic amino acids in heparin binding sites. Arch Biochem Biophys. 1997;343(1):92-100.

22. Gandhi NS, Mancera RL. The structure of glycosaminoglycans and their interactions with proteins. Chem Biol Drug Des. 2008;72(6):455-82.

23. Gavine PR, Mooney L, Kilgour E, Thomas AP, Al-Kadhimi K, Beck S, Rooney C, Coleman T, Baker D, Mellor MJ, et al. AZD4547: an orally bioavailable, potent, and selective inhibitor of the fibroblast growth factor receptor tyrosine kinase family. Cancer Res. 2012;72(8):2045-56.

24. Mohammadi M, Froum S, Hamby JM, Schroeder MC, Panek RL, Lu GH, Eliseenkova AV, Green D, Schlessinger J, Hubbard SR. Crystal structure of an angiogenesis inhibitor bound to the FGF receptor tyrosine kinase domain. EMBO J. 1998;17(20):5896-904.

25. Sanvitale CE, Kerr G, Chaikuad A, Ramel MC, Mohedas AH, Reichert S, Wang Y, Triffitt JT, Cuny GD, Yu PB, et al. A new class of small molecule inhibitor of BMP signaling. PLoS One. 2013;8(4):e62721.

26. Inman GJ, Nicolas FJ, Callahan JF, Harling JD, Gaster LM, Reith AD, Laping NJ, Hill CS. SB-431542 is a potent and specific inhibitor of transforming growth factor-beta superfamily type I activin receptor-like kinase (ALK) receptors ALK4, ALK5, and ALK7. Mol Pharmacol. 2002;62(1): 65-74.

27. Ogunjimi AA, Zeqiraj E, Ceccarelli DF, Sicheri F, Wrana JL, David L. Structural basis for specificity of TGFbeta family receptor small molecule inhibitors. Cell Signal. 2012;24(2):476-83.

28. Tojo M, Hamashima Y, Hanyu A, Kajimoto T, Saitoh M, Miyazono K, Node M, Imamura T. The ALK-5 inhibitor A-83-01 inhibits Smad signaling and epithelial-to-mesenchymal transition by transforming growth factor-beta. Cancer Sci. 2005;96(11):791-800.

29. Wu GS, Robertson DH, Brooks CL, Vieth M. Detailed analysis of grid-based molecular docking: a case study of CDOCKER - a CHARMm-based MD docking algorithm. J Comput Chem. 2003;24(13):1549-62.

30. Schlessinger J, Plotnikov AN, Ibrahimi OA, Eliseenkova AV, Yeh BK, Yayon A, Linhardt RJ, Mohammadi M. Crystal structure of a ternary FGF-FGFR-heparin complex reveals a dual role for heparin in FGFR binding and dimerization. Mol Cell. 2000;6(3):743-50.

31. Shen YM, Maupetit J, Derreumaux P, Tuffery P. Improved PEP-FOLD approach for peptide and miniprotein structure prediction. J Chem Theory Comput. 2014;10(10):4745-58.

32. Jo S, Kim T, lyer VG, Im W. CHARMM-GUI: a web-based graphical user interface for CHARMM. J Comput Chem. 2008;29(11):1859-65.
33. Mark JA, Teemu M, Roland S, Szilárd P, Jeremy CS, Berk H, Erik L. GROMACS: high performance molecular simulations through multi-level parallelism from laptops to supercomputers. SoftwareX. 2015;1-2:19-25.

34. Huang J, Rauscher S, Nawrocki G, Ran T, Feig M, de Groot BL, Grubmuller H, Mackerell AD. CHARMM36m: an improved force field for folded and intrinsically disordered proteins. Nat Methods. 2017;14(1):71-3.

35. Jorgensen WL, Chandrasekhar J, Madura JD, Impey RW, Klein ML. Comparison of simple potential functions for simulating liquid water. J Chem Phys. 1983;79(2):926-35.

36. Essmann U, Perera L, Berkowitz ML, Darden T, Lee H, Pedersen LG. A smooth particle mesh Ewald method. J Chem Phys. 1995;103(19):8577-93.

37. Hess B, Bekker H, Berendsen HJC, Fraaije J. LINCS: a linear constraint solver for molecular simulations. J Comput Chem. 1997;18(12):1463-72.

38. Miyamoto S, Kollman PA. Settle - an analytical version of the shake and rattle algorithm for rigid water models. J Comput Chem. 1992;13(8):952-62.

39. Nose S. A molecular dynamics method for simulations in the canonical ensemble. Mol Phys. 1984:52(2):255-68.

40. Parrinello M, Rahman A. Polymorphic transitions in single crystals: a new molecular dynamics method. J Appl Phys. 1981;52(12):7182-90.

41. Zorko M, Langel U. Cell-penetrating peptides: mechanism and kinetics of cargo delivery. Adv Drug Deliv Rev. 2005;57(4):529-45.

42. Yosaatmadja Y, Patterson AV, Smaill JB, Squire CJ. The 1.65 angstrom resolution structure of the complex of AZD4547 with the kinase domain of FGFR1 displays exquisite molecular recognition. Acta Crystallographica Section D-Biological Crystallography. 2015:71:525-33.

43. Del Piccolo N, Sarabipour S, Hristova K. A new method to study heterodimerization of membrane proteins and its application to fibroblast growth factor receptors. J Biol Chem. 2017;292(4):1288-301.

44. Ying QL, Wray J, Nichols J, Batlle-Morera L, Doble B, Woodgett J, Cohen P, Smith A. The ground state of embryonic stem cell self-renewal. Nature. 2008;453(7194):519-U515.

45. Kunath T, Saba-El-Leil MK, Almousailleakh M, Wray J, Meloche S, Smith A. FGF stimulation of the Erk1/2 signalling cascade triggers transition of pluripotent embryonic stem cells from self-renewal to lineage commitment. Development. 2007;134(16):2895-902

46. Plotnikov AN, Schlessinger J, Hubbard SR, Mohammadi M. Structural basis for FGF receptor dimerization and activation. Cell. 1999;98(5):641-50.

47. Mohammadi M, Olsen SK, Ibrahimi OA. Structural basis for fibroblast growth factor receptor activation. Cytokine Growth Factor Rev. 2005;16(2):107-37.

48. Mohammadi M, Olsen SK, Goetz R. A protein canyon in the FGF-FGF receptor dimer selects from an a la carte menu of heparan sulfate motifs. Curr Opin Struct Biol. 2005:15(5):506-16.

49. Groppe J, Hinck CS, Samavarchi-Tehrani P, Zubieta C, Schuermann JP, Taylor AB, Schwarz PM, Wrana JL, Hinck AP. Cooperative assembly of TGF-beta superfamily signaling complexes is mediated by two disparate mechanisms and distinct modes of receptor binding. Mol Cell. 2008;29(2):157-68.

50. Eswarakumar VP, Lax I, Schlessinger J. Cellular signaling by fibroblast growth factor receptors. Cytokine Growth Factor Rev. 2005;16(2):139-49.

51. Lemmon MA, Schlessinger J. Cell signaling by receptor tyrosine kinases. Cell. 2010:141(7):1117-34.

52. Beenken A, Mohammadi M. The FGF family: biology, pathophysiology and therapy. Nat Rev Drug Discov. 2009;8(3):235-53.

53. Weiss A, Attisano L. The TGFbeta superfamily signaling pathway. Wiley Interdiscip Rev Deve Biol. 2013;2(1):47-63.

54. Wrana JL, Attisano L, Wieser R, Ventura F, Massague J. Mechanism of activation of the TGF-beta receptor. Nature. 1994;370(6488):341-7.

55. Guerrero-Esteo M, Sanchez-Elsner T, Letamendia A, Bernabeu C. Extracellular and cytoplasmic domains of endoglin interact with the transforming growth factor-beta receptors I and II. J Biol Chem. 2002;277(32):29197-209.

56. Esparza-Lopez J, Montiel JL, Vilchis-Landeros MM, Okadome T, Miyazono K, Lopez-Casillas F. Ligand binding and functional properties of betaglycan, a co-receptor of the transforming growth factor-beta superfamily. Specialized binding regions for transforming growth factor-beta and inhibin A. J Biol Chem. 2001;276(18):14588-96.

57. Jenkins LM, Horst B, Lancaster CL, Mythreye K. Dually modified transmembrane proteoglycans in development and disease. Cytokine Growth Factor Rev. 2018;39:124-36.

58. Greenwald J, Fischer WH, Vale WW, Choe S. Three-finger toxin fold for the extracellular ligand-binding domain of the type II activin receptor serine kinase. Nat Struct Biol. 1999:6(1):18-22. 
59. Andres JL, DeFalcis D, Noda M, Massague J. Binding of two growth factor families to separate domains of the proteoglycan betaglycan. J Biol Chem 1992;267(9):5927-30.

60. Takacs Z, Nathan, S.: Animal venoms in medicine. In: Wexler, P (Ed),

Encyclopedia of toxicology 2014:3rd edition,Vol 1.Amsterdam:Elsevier Inc., Academic Press:2014.p.252-3259.

\section{Publisher's Note}

Springer Nature remains neutral with regard to jurisdictional claims in published maps and institutional affiliations.

Ready to submit your research? Choose BMC and benefit from:

- fast, convenient online submission

- thorough peer review by experienced researchers in your field

- rapid publication on acceptance

- support for research data, including large and complex data types

- gold Open Access which fosters wider collaboration and increased citations

- maximum visibility for your research: over $100 \mathrm{M}$ website views per year

At BMC, research is always in progress.

Learn more biomedcentral.com/submissions 